\title{
An experimental test of the role of structural blue and melanin-based chestnut coloration in aggressive contests in male eastern bluebirds
}

\author{
Austin Mercadante and Geoffrey E. Hill * \\ Department of Biological Sciences, Auburn University, Auburn, AL, USA
}

\section{Edited by:}

Wayne Iwan Lee Davies, University

of Western Australia, Australia

\section{Reviewed by:}

Dustin R. Rubenstein, Columbia

University, USA

David M. Hunt, University of

Western Australia, Australia

*Correspondence:

Geoffrey E. Hill, Department of

Biological Sciences, Auburn

University, 331 Funchess Hall,

Auburn, AL 36849-5414, USA

e-mail: ghill@auburn.edu
Male eastern bluebirds (Sialia sialis) have feathers with either structurally based blue coloration or melanin-based chestnut coloration, and they hold territories during the breeding season that they defend vigorously. We tested whether the melanin pigmentation or structural coloration of feathers serve as signals during intrasexual aggressive encounters by placing color-modified stuffed bluebirds in male territories. We recorded the time to attack and the intensity of attacks on each model, and we then compared the response to color-enhanced vs. color-reduced models. Male bluebirds attacked models with brighter and more chromatic blue coloration significantly more often than they attacked models with darker and less chromatic blue coloration. In contrast, the darkness of the chestnut breast coloration did not have a significant effect on the rate at which models were attacked. We conclude that territorial male bluebirds perceive intruding males with brighter blue coloration as a greater threat than males with drabber blue coloration, presumably because blue coloration is a signal of fighting ability. In contrast, the chestnut coloration of breast feathers appears to be a signal of gender and sexual maturity and not a graded signal of social status.

\section{Keywords: plumage color, structural coloration, melanin coloration, aggression, territoriality}

\section{INTRODUCTION}

Sexual selection on a trait can arise either through female mate choice for the trait or through advantages that result from the trait in male-male interactions (Darwin, 1871; Andersson, 1994; Hill, 2014). The means by which armaments like horns, spurs, or large body size can facilitate competition for mates is straightforward and has never been disputed (Cronin, 1991). Less intuitive is the mechanism by which visual displays can arise through malemale competition. There is now an abundance of evidence from studies of diverse taxa that visual displays can serve as signals of male fighting ability and that these signals can mediate contests between males (Andersson, 1994; Berglund et al., 1996; Tibbetts, in press).

Within the context of competition among all males in a population, both dominant and subordinate males benefit from honest signaling of status (Rohwer, 1982; Senar, 2006). Through status signaling, dominant males avoid wasting time and energy engaging in contests with lower-status males, and subordinate males benefit by avoiding dangerous interactions with dominant individuals (Rohwer, 1975; Lyon and Montgomerie, 1986; Hawkins et al., 2012). In a status-signaling system, cheating is prevented either by the high cost of constructing or maintaining an ornament (Zahavi, 1975; Owens and Hartley, 1991) or by the high social costs of dishonestly signaling status (Rohwer, 1977; Ketterson, 1979; Moller, 1987; Tibbetts, in press). Therefore, status signals can be used by birds as honest indicators of a rival's age, rank, or fighting ability (Fugle et al., 1984; Jarvi and Bakken, 1984; Senar, 2006).

In species that defend exclusive territories containing critical resources, all territory-holding individuals are winners with good fighting ability (Lack, 1968; Ligon, 1999; Hill, 2010). Among such males, the benefits of retaining a territory are very high as are the costs of losing a territory. The entire lifetime reproductive success of a territorial male bird often hinges on its ability to defend and retain its territory (Lack, 1968; Ligon, 1999). Assessments of rivals made by territorial males in such circumstances do not concern whether or not to fight; they are about how aggressively they fight. Males signaling high fighting ability pose the greatest threat to a territorial male and are predicted to elicit the strongest response. Males signaling reduced fighting ability pose less of a threat and are predicted to be met with a less intense response (Ligon, 1999; Hill, 2010).

We studied the role of plumage coloration in aggressive interactions in the eastern bluebird (Sialia sialis). Male eastern bluebirds have bright blue coloration on their heads, backs, tails, and rumps and bold chestnut coloration across their breasts (Figure 1). The structural blue coloration results from coherent scattering of light from the spongy layer of feather barbs (Shawkey et al., 2003; Prum, 2006), while chestnut breast coloration results from melanin pigmentation (McGraw et al., 2004). Most structural plumage coloration reflects light in the ultraviolet (UV) region of the spectrum as well as the visible spectrum (Prum, 2006). Female songbirds can perceive both the human-visible and 


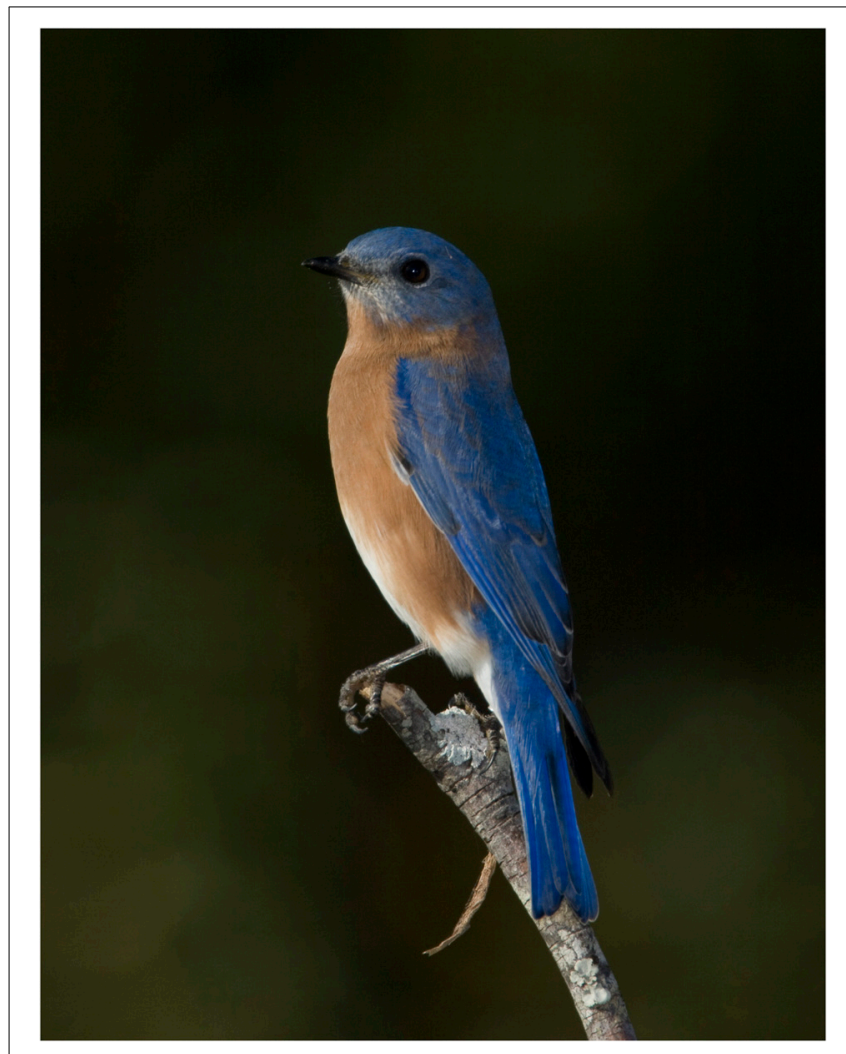

FIGURE 1 | A male eastern bluebird in Auburn, Alabama. The two prominent ornaments of eastern bluebirds are the bright blue dorsal plumage and bold chestnut breast plumage. Photograph by Geoffrey E. Hill.

UV light reflected from feathers (Hart et al., 2000; Hunt and Peichl, 2014). Previous research has shown that, within populations, males show substantial variation in the brightness and chroma of blue coloration as well as in the brightness of chestnut breast coloration (Siefferman and Hill, 2003).

Male eastern bluebirds are highly territorial during the breeding season (Gowaty and Plissner, 1998). Successful males defend territories that contain a nesting cavity, without which they cannot breed, as well as space for exclusive foraging (Gowaty and Plissner, 1998; Siefferman and Hill, 2005b). Male bluebirds are highly aggressive in defense of territories. They permit no other males in their defended space (Gowaty and Plissner, 1998). Removal experiments indicate that male bluebirds that hold territories are a subgroup of all males in the local population. Vacated territories are quickly filled by males who previously held no territory (Siefferman and Hill, 2005b). In an experiment in which a first set of boxes were placed in fields a month before a second set of boxes was added, males that won occupancy of the first boxes had significantly brighter blue coloration than males that occupied boxes placed later (Siefferman and Hill, 2005b). This experiment suggests that blue color mediated dominance interactions among eastern bluebirds, but the role of individual variation in blue and chestnut color in aggressive interactions has not been tested directly in bluebirds.
To test the role of blue and chestnut plumage coloration in assessments of fighting ability, we manipulated coloration on taxidermic models of eastern bluebird males and then presented the models to resident bluebirds during the breeding season. We first manipulated blue coloration while holding chestnut color constant and then manipulated chestnut coloration, while holding blue coloration constant. In our manipulations of blue coloration we matched natural light patterns of light absorption and reflection in both the UV and human visible portions of the spectrum. Bluebirds display threatening postures including bill wiping, wing flapping, and singing toward taxidermic mounts in their territory and will violently attack a model bluebird that remains in the territory (Hill, 2010). We predicted that if individual variation in plumage coloration functions as a signal of fighting ability, then territorial male bluebirds would show a heightened aggression toward more ornamented intruders (brighter or more chromatic blue coloration and darker chestnut coloration). By using models, we reduced the problems of interactive behavior between live models and resident pairs that can override any potential signal function of coloration (Senar, 2006). Furthermore, by artificially manipulating the blue and chestnut coloration of eastern bluebirds, we tested for the importance of structural and melanin feather coloration independent of each other and independent of the age or body condition.

\section{METHODS}

We studied eastern bluebirds on agricultural fields and pastures adjacent in Lee County, Alabama $\left(32^{\circ} 35^{\prime} \mathrm{N}, 82^{\circ} 28^{\prime} \mathrm{W}\right.$; see Siefferman and Hill (2003) for details of study area). We conducted behavioral experiments during egg laying and chick rearing of first broods when male aggression is high (Gowaty and Wagner, 1988). Males are territorial and will attack conspecifics that encroach upon their territory. To test whether the brightness of male bluebird coloration affects aggressive behaviors in territorial males, we used taxidermic mounts constructed from salvaged carcasses of eastern bluebirds as models to which we artificially manipulated the brightness of the plumage.

In 2009, we increased the brightness and chroma of the structurally based blue coloration on the wings, backs, and tails of six models with a violet marker (Prismacolor ${ }^{\circledR}$ PM-60: violet mist) and decreased the coloration with a black permanent marker (Sharpie ${ }^{\circledR}$ permanent marker: black) following the procedures in (Liu et al., 2007) on six models. To a human observer, there is little variation in coloration among male bluebirds and our treatments appeared to have subtle effects on the appearance of the models. This poor perception of structural coloration is likely a consequence of most of the variable wavelengths falling outside or near the periphery of human color perception. Spectrometric analysis showed that our manipulations pushed males toward the extremes of bright and drab coloration observed within populations (Figure 2). The degree of color change caused by our marker treatment would have been readily visible to an eastern blue bluebird (Liu et al., 2007).

In 2010, we increased the chroma of the melanin-based chestnut coloration on a male bluebird's breast using a brown marker (Prismacolor ${ }^{\circledR}$ PM-90: Walnut) and decreased the coloration using hydrogen peroxide (White et al., 1980) to bleach 


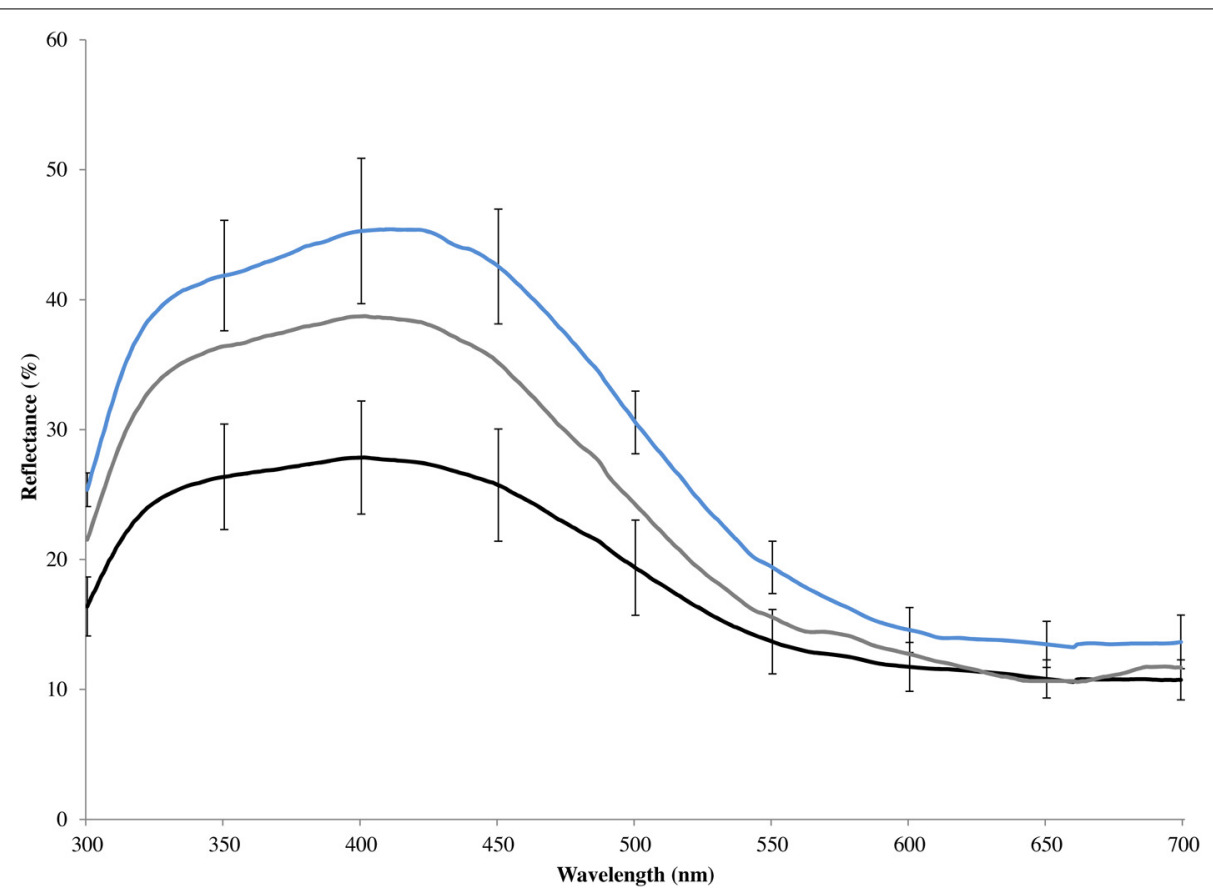

FIGURE 2 | Mean spectral reflectance of blue rump feathers of eastern bluebirds, including unmanipulated males (gray line), artificially brightened models constructed from male carcasses (blue line), and artificially darkened models constructed from male carcasses (black line). Error bars show 95\% confidence intervals. the feathers. The effects of our color manipulation on breast coloration was more obvious to a human observer than were the effects of blue manipulation, likely because all of the color variation occurred within wavelengths that are readily perceived by humans. The effect of the breast color manipulation as measured by a spectrophotometer, however, was smaller (Figure 3). In both cases, we pushed coloration toward the extremes of dark and light plumage seen in our study population (Figures 2, 3), so our tests of the responses to the models should be relevant to how wild male eastern bluebirds respond to brightly or drably colored intruders. As with the tests of structural coloration, we used six different pairs of models to minimize the influence of the idiosyncrasies of any single model.

To measure the effect that our manipulation had on feather coloration, we quantified the coloration of feathers using an Ocean Optics S2000 spectrometer (Dunedin, Florida). We took measurements at $90^{\circ}$ incident and reflective angles. For both blue and chestnut coloration, we calculated brightness as the mean summed reflectance $\left(\mathrm{R}_{300-700} \mathrm{~nm}\right)$. For blue coloration, we calculated UV chroma as the proportion of the total reflectance $\left(\mathrm{R}_{300-700} \mathrm{~nm}\right)$ in the UV part of the spectrum $\left(\mathrm{R}_{300-400} \mathrm{~nm}\right)$. Color parameters are correlated in eastern bluebirds such that the most-ornamented UV-blue males display brighter coloration, greater UV chroma, and hues with wavelengths shifted toward the shorter wavelengths (Siefferman et al., 2005).

During both years we followed the same protocol: we drove two, $1.2 \mathrm{~m}$ metal poles into the ground $5 \mathrm{~m}$ from a bluebird nest box and $5 \mathrm{~m}$ apart. Atop each pole we placed a taxidermic bluebird model attached to a $1.2 \mathrm{~m}$ wooden dowel (diameter $1 \mathrm{~cm}$ ) placed perpendicular to the pole. The dowel gave responding bluebirds a place to perch near the model and display before attacking. One darkened model and one brightened model were simultaneously displayed to a breeding pair while a speaker repeatedly played a $30 \mathrm{~s}$ clip of bluebird songs between them. We randomly chose one model from the bright category and one model from the drab category for each trial. Thus, there were 36 potential model combinations.

Models were covered with a paper bag and then simultaneously exposed by pulling the bags off the models using thin fishing line (following procedures in Ligon and Hill, 2009). We played bluebird songs for $5 \mathrm{~min}$ before exposing the models and throughout the trial to ensure that the resident bluebirds were attentive to the models and searching for an intruding adult male before the models were presented. Observations were made from a concealed location $>30 \mathrm{~m}$ from the nest box.

The trial began and we started recording bluebird behaviors when the models were exposed. We stopped trials after 10 min or when a model was physically attacked to preserve model condition for later trials, and models remained undamaged through the experiment. We quantified which model received the first signs of aggression and which model received the most aggressive attacks. We also recorded the amount of time until the models were attacked. We did not calculate the repeatability of male behaviors by exposing individual males more than once. Exposing males to the models multiple 


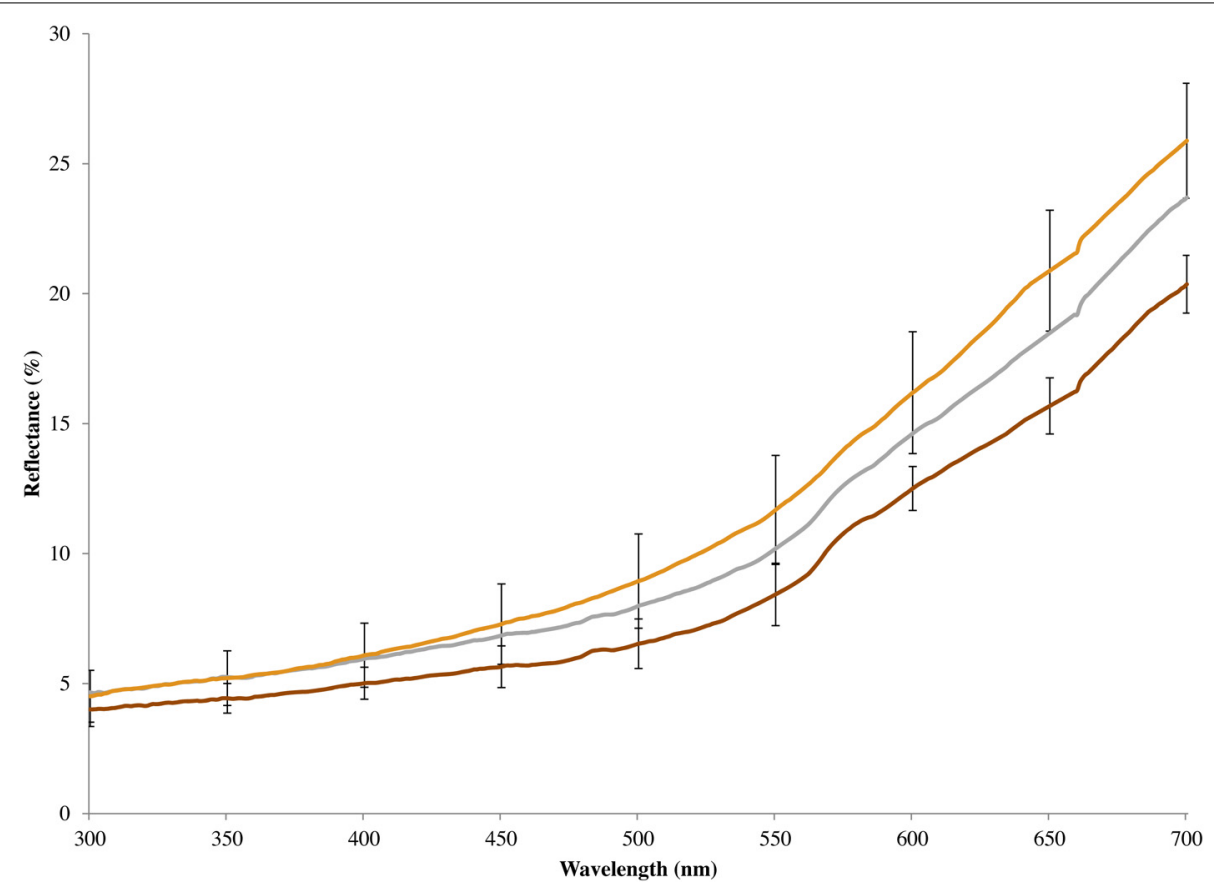

FIGURE 3 | Mean spectral reflectance of chestnut breast feathers of eastern bluebirds, including unmanipulated males (gray line), artificially brightened models constructed from male carcasses (tan line), and artificially darkened models constructed from male carcasses (brown line). Error bars show 95\% confidence intervals. times would have induced variable levels of habituation that would have made it hard to estimate heritability and simulating multiple intrusion would have unduly harassed individual males.

We used a Chi-squared test to compare the observed number of times the brighter model was attacked first relative to our expected, or null hypothesis, that color did not impact which model was attacked first. In trials where the model receiving the most aggression was dissimilar to the model that was first attacked, we used a Fisher's exact test to determine if the change was random of the switch more likely to be from the drab model to the bright model than vise versa. A Chi-squared test was also used to determine ifdarker breast coloration differed from parity.

\section{RESULTS}

We presented models with manipulated blue coloration to 66 different territorial males. Seven of these the 66 males did not approach either of the models and we not observed during the trial period, and we excluded those seven males from our analyses. Of the remaining 59 trials, resident males first attacked the blue brightened model in 39 trials and the drabber blue model in 20 trials $\left(X^{2}=4.90, N=59, P=0.03\right.$, Figure 4). The blue brightened model was attacked most aggressively in 48 of the 59 trials $(81 \%)$. Among the 11 trials in which the model receiving the most aggression differed from the model receiving the first aggression, the responding male switched the focus of attack from the drab to the bright model in six trials $(55 \%)$ and from the bright to the drab model

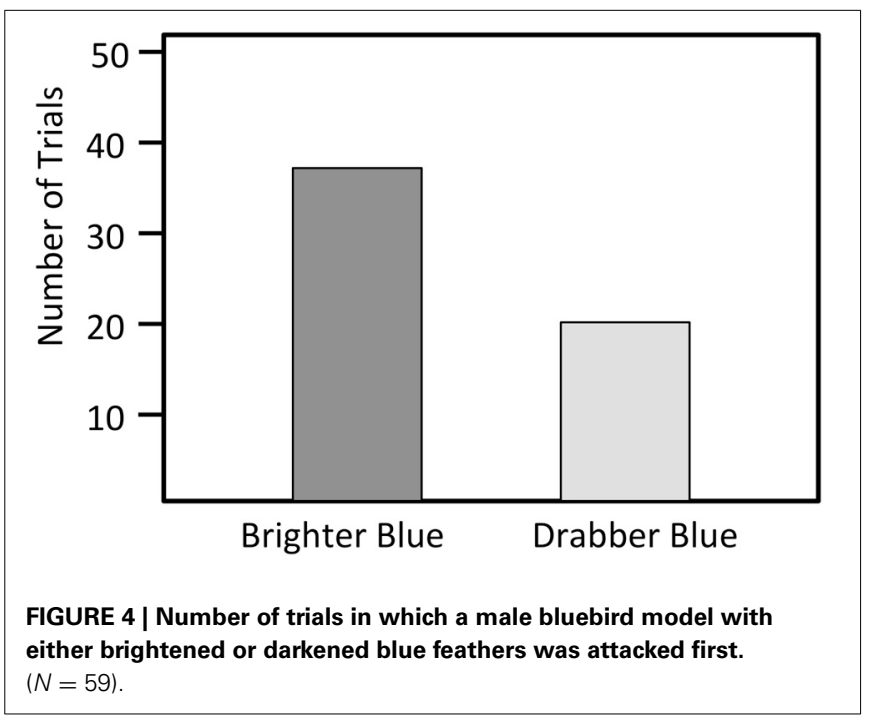

in five trials $(45 \%)$, indicating that the attacks of these males were not focused on a particular model (Fisher's exact test, $P=0.99)$.

We presented models with breast color manipulated to 36 different territorial males. The marker treatments on breast plumage had no significant effect on the responses of territorial males. Resident males first approached the model with darker chest coloration in 16 trials, and they first approached the model with lighter chest coloration in 20 trials $\left(X^{2}=1.78 \mathrm{~N}=36, P=0.18\right.$; Figure 5). 


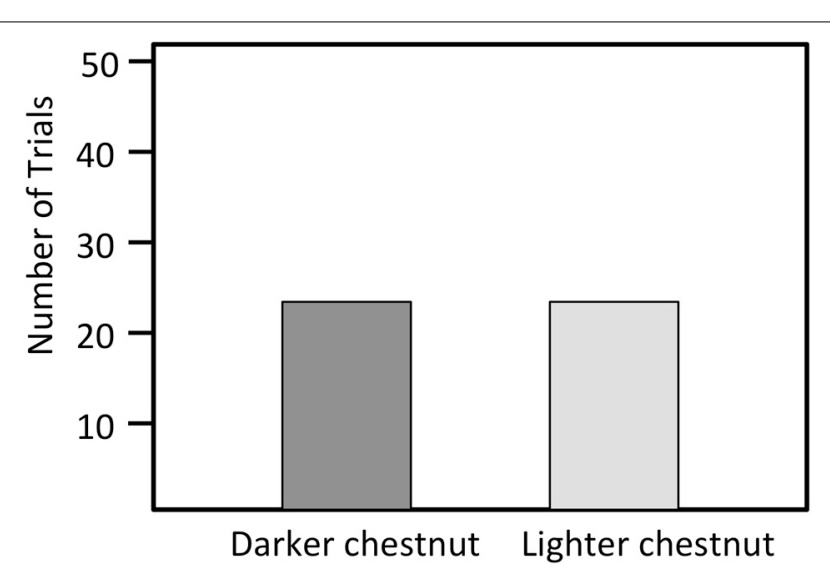

FIGURE 5 | Number of trials in which a male bluebird model with either lightened or darkened chestnut breast feathers was attacked first. $(N=36)$.

\section{DISCUSSION}

Previous studies showed that blue coloration but not chestnut coloration is associated with individual quality in eastern bluebirds. Brightness and chroma of structural blue coloration of males was correlated with earlier breeding and greater number of offspring fledged (Siefferman and Hill, 2003, 2005a,b); juveniles in less crowded nests grew brighter feathers than juveniles in more crowded nests (Siefferman and Hill, 2007); and, females subjected to food stress grew less colorful feathers than females that were not food stressed (Siefferman and Hill, 2005a). Studies of other species of passerine birds have also found positive relationships between individual condition and the brightness or chroma of structural coloration but rarely between condition and expression of chestnut phaeomelanin coloration (reviewed in Hill, 2006).

Previous tests of the function of blue coloration in birds have generated ambiguous results. Experiments with blue tits (Cyanistes caeruleus) and European starlings (Sturnus vulgaris) revealed female mate choice for bright and chromatic structural coloration (Bennett et al., 1997; Andersson et al., 1998), but a subsequent study with blue tits found no choice for UV crown coloration (Kurvers et al., 2010). Controlled mate choice experiments with blue grosbeaks (Passerina caerulea) and eastern bluebirds demonstrated that females of those species do no use male structural coloration as an important criterion in mate choice (Ballentine and Hill, 2003; Liu et al., 2007, 2009). Studies of dominance in relation to structural plumage coloration have been conducted on blue tits, and various studies both supported and refuted the hypothesis that brighter blue/UV coloration is a signal of fighting ability (Alonso-Alvarez et al., 2004; Korsten et al., 2007; Vedder et al., 2010).

Given that blue coloration of eastern bluebirds is known to relate to individual condition and that female bluebirds do not appear to use male coloration as a criterion in mate choice, we hypothesized that blue coloration may play a role in signaling resource holding potential. In support of this hypothesis, we found that male eastern bluebirds altered their aggressive behavior toward models in response to experimental modifications in structural-based blue feather coloration. Males attacked conspecific models that were artificially brightened significantly more often than they attacked artificially dulled models.

The observation that male fighting ability is signaled by the brightness and chroma of blue structural coloration is consistent with observations from previous studies of blueness and territory acquisition by male eastern bluebirds on the same study area. In an experiment in which nest boxes were placed in pastures that represented excellent bluebird breeding habitat, but that lacked any nest sites, males that gained ownership of the first set of boxes were significantly brighter and more chromatic than males that won boxes erected later (Siefferman and Hill, 2005a,b). Presumably, brighter males acquired the first boxes because they held higher social status. The current study provides experimental evidence that blue coloration alters the aggressive behavior of territory males in a pattern consistent with the hypothesis that bluer males have higher resource holding potential.

In contrast to the significant effect of structural coloration of models on the rates at which they were attacked, differences in chestnut breast coloration among models did not have a significant affect how territorial males responded to them. Variation in the boldness of the chestnut breast display of eastern bluebirds does not appear to affect how the signal is perceived by conspecifics. These observations may seem at odds with the extensive literature on melanin coloration and social status in which melanin ornaments are consistently positively related to resource holding potential (Senar, 2006). However, the great majority of studies of melanin coloration and dominance have focused on badge size and not coloration per se and most studies focused on black eumelanin coloration rather than brown phaeomelanin coloration (Senar, 2006). Territorial male eastern bluebirds have been shown to respond strongly to models with orange breasts compared to models with plain white or white spotted breasts (Ligon and Hill, 2009). Here we show that, within the range of variation shown by adult males in a population, the chestnut breast coloration of male bluebirds appears not to serve as a graded signal of social status in eastern bluebirds. Taken together, these observations support the idea that chestnut breast coloration of bluebirds serves as a signal of gender and sexual maturity (Ligon and Hill, 2009; Hawkins et al., 2012) and not fighting ability perse.

The implications of our studies of the responses of males to chestnut and blue coloration are that these two color patches serve different but equally important functions. A male bluebird faced with an intruder first assesses breast coloration to gauge whether the intruder is a threat worthy of time and effort by observing whether or not it has an orange breast. If the intruder is a rival males as signaled by its orange breast then the territorial male assesses blueness to gain information about likely fighting ability. Males with brighter blue plumage are signaling higher status and are more of a threat around nests than males with drabber blue plumage. By having no orange feathers, juvenile bluebirds avoid aggression from adult 
males (Ligon and Hill, 2009). By having breast coloration so drab that it is below the range of variation among males (and below the level of manipulation used in this study), female bluebirds also avoid most male aggression. Only orangebreasted adult males invoke a response from males and that response is adjusted to the fighting ability as signaled by blue plumage.

\section{ACKNOWLEDGMENT}

This work was supported by grants (IBN 0235778 and DEB 0077804) to Geoffrey E. Hill from the National Science Foundation.

\section{REFERENCES}

Alonso-Alvarez, C., Doutrelant, C., and Sorci, G. (2004). Ultraviolet reflectance affects male-male interactions in the blue tit (Parus caeruleus ultramarinus). Behav. Ecol. 15, 805-809. doi: 10.1093/beheco/arh083

Andersson, M. (1994). Sexual Selection. Princeton, NJ: Princeton University Press.

Andersson, S., Ornborg, J., and Andersson, M. (1998). Ultraviolet sexual dimorphism and assortative mating in blue tits. Proc. R. Soc. Lond. B Biol. 265, 445-450. doi: 10.1098/rspb.1998.0315

Ballentine, B., and Hill, G. E. (2003). Female mate choice in relation to structural plumage coloration in blue grosbeaks. Condor 105, 593-598. doi: 10.1650/7234

Bennett, A. T. D., Cuthill, I. C., Partridge, J. C., and Lunau, K. (1997). Ultraviolet plumage colors predict mate preferences in starlings. Proc. Natl. Acad. Sci. U.S.A. 94, 8618-8621. doi: 10.1073/pnas.94.16.8618

Berglund, A., Bisazza, A., and Pilastro, A. (1996). Armaments and ornaments: an evolutionary explanation of traits of dual utility. Biol. J. Linn. Soc. 58, 385-399. doi: 10.1111/j.1095-8312.1996.tb01442.x

Cronin, H. (1991). The Ant and the Peacock. Cambridge: Cambridge University Press.

Darwin, C. (1871). The Descent of Man, and Selection in Relation to Sex. London: Murray. doi: 10.1037/12293-000

Fugle, G. N., Rothstein, S. I., Osenberg, C. W., and McGinley, M. A. (1984). Signals of status in wintering white-crowned sparrows, Zonotrichia leucophrys gambelii. Anim. Behav. 32, 86-93. doi: 10.1016/S0003-3472(84)80327-9

Gowaty, P. A., and Plissner, J. H. (1998). "Eastern bluebird," in Birds of North America, eds A. Poole and F. Gill (Philadelphia, PA: The Birds of North America Inc), 1-32.

Gowaty, P. A., and Wagner, S. J. (1988). Breeding season aggression of female and male eastern bluebirds (Sialia sialis) to models of potential conspecific and interspecific egg dumpers. Ethology 78, 238-250. doi: 10.1111/j.14390310.1988.tb00234.x

Hart, N. S., Partridge, J. C., Cuthill, I. C., and Bennett, A. T. (2000). Visual pigments, oil droplets, ocular media and cone photoreceptor distribution in two species of passerine bird: the blue tit (Parus caeruleus L.) and the blackbird (Turdus merula L.). J. Comp. Physiol. A 186, 375-387. doi: 10.1007/s003590050437

Hawkins, G. L., Hill, G. E., and Mercadante, A. (2012). Delayed plumage maturation and delayed reproductive investment in birds. Biol. Rev. 87, 257-274. doi: 10.1111/j.1469-185X.2011.00193.x

Hill, G. E. (2006). "Environmental regulation of ornamental coloration,” in Bird Coloration. Meachanisms and Measurements, Vol. 1, eds G. E. Hill and K. J. McGraw (Cambridge, MA: Harvard University Press), 507-560.

Hill, G. E. (2010). National Goegraphic Bird Coloration. Washington, DC: National Geographic Society.

Hill, G. E. (2014). "The evolution of ornaments and armaments," in Animal Behavior: How and Why Animals Do the Things They Do, Vol. 2, Function and Evolution, ed K. Yasukawa (Santa Barbara, CA: Praeger/ABC-CLIO), 145-172.

Hunt, D. M., and Peichl, L. (2014). S cones: evolution, retinal distribution, development and spectral sensitivity.Vis. Neurosci. 31, 115-138. doi: $10.1017 /$ S0952523813000242

Jarvi, T., and Bakken, M. (1984). The function of the variation in the breast stripe of the great tit (Parus major). Anim. Behav. 32, 590-596. doi: 10.1016/S00033472(84)80296-1

Ketterson, E. D. (1979). Status signaling in dark-eyed juncos. Auk 96, 94-99.
Korsten, P., Vedder, O., Szentirmai, I., and Komdeur, J. (2007). Absence of status signalling by structurally based ultraviolet plumage in wintering blue tits (Cyanistes caeruleus). Behav. Ecol. Sociobiol. 61, 1933-1943. doi: 10.1007/s00265-007-0433-z

Kurvers, R. H., Delhey, K., Roberts, M. L., and Peters, A. (2010). No consistent female preference for higher crown UV reflectance in blue tits Cyanistes caeruleus: a mate choice experiment. Ibis 152, 393-396. doi: 10.1111/j.1474919X.2009.00998.x

Lack, D. M. (1968). Ecological Adaptations for Breeding in Birds. London: Methuen.

Ligon, J. D. (1999). The Evolution of Avian Breeding Systems. Oxford: Oxford University Press.

Ligon, R. A., and Hill, G. E. (2009). Do adult eastern bluebird, Sialia sialis, males recognize juvenile-specific traits? Anim. Behav. 77, 1267-1272. doi: 10.1016/j.anbehav.2009.01.031

Liu, M., Siefferman, L., and Hill, G. E. (2007). An experimental test of female choice relative to male structural coloration in eastern bluebirds. Behav. Ecol. Sociobiol. 61, 623-630. doi: 10.1007/s00265-006-0292-z

Liu, M., Siefferman, L., Mays, H., Steffen, J. E., and Hill, G. E. (2009). A field test of female mate preference for male plumage coloration in eastern bluebirds. Anim. Behav. 78, 879-885. doi: 10.1016/j.anbehav.2009. 07.012

Lyon, B. E., and Montgomerie, R. D. (1986). Delayed plumage maturation in passerine birds: reliable signaling by subordinate males? Evolution 40, 605-615. doi: $10.2307 / 2408581$

McGraw, K. J., Wakamatsu, K., Ito, S., Nolan, P. M., Jouventin, P., Dobson, F. S., et al. (2004). You can't judge a pigment by its color: carotenoid and melanin content of yellow and brown feathers in swallows, bluebirds, penguins, and domestic chickens. Condor 106, 390-395. doi: 10.1650/7384

Moller, A. P. (1987). Social control of deception among status signaling house sparrows passer domesticus. Behav. Ecol. Sociobiol. 20, 307-311. doi: 10.1007/BF00300675

Owens, I. P. F., and Hartley, I. R. (1991). “Trojan Sparrows:” evolutionary consequences of dishonest invasion for the badges-of-status model. Am. Nat. 138, 1187-1205. doi: 10.1086/285277

Prum, R. E. O. (2006). "Anatomy, Physics, and Evolution of Structural Colors," in Bird Coloration. Mechanisms and Measurements, Vol. 1, eds G. E. Hill and K. J. McGraw (Cambridge, MA: Harvard University Press), 295-353.

Rohwer, S. (1975). The social significance of avian winter plumage variability. Evolution 29, 593-610. doi: 10.2307/2407071

Rohwer, S. (1977). Status signaling in Harris' sparrows: some experiments in deception. Behaviour 61, 107-128. doi: 10.1163/156853977X00504

Rohwer, S. (1982). The evolution of reliable and unreliable badges of fighting ability. Am. Zool. 22, 531-546.

Senar, J. C. (2006). "Color displays as intrasexual signals of aggression and dominance," in Bird Coloration, Function and Evolution, Vol. 2, eds G. E. Hill and K. J. McGraw (Cambridge, MA: Harvard University Press), 87-136.

Shawkey, M. D., Estes, A. M., Siefferman, L. M., and Hill, G. E. (2003). Nanostructure predicts intraspecific variation in ultraviolet-blue plumage colours. Proc. R. Soc. Lond. B Biol. 270, 1455-1460. doi: 10.1098/rspb. 2003.2390

Siefferman, L., and Hill, G. E. (2003). Structural and melanin coloration indicate parental effort and reproductive success in male eastern bluebirds. Behav. Ecol. 14, 855-861. doi: 10.1093/beheco/arg063

Siefferman, L., and Hill, G. E. (2005a). Evidence for sexual selection on structural plumage coloration in female eastern bluebirds (Sialia sialis). Evolution 59, 1819-1828. doi: 10.1111/j.0014-3820.2005. tb01828.x

Siefferman, L., and Hill, G. E. (2005b). UV-blue structural coloration and competition for nestboxes in male eastern bluebirds. Anim. Behav. 69, 67-72. doi: 10.1016/j.anbehav.2003.12.026

Siefferman, L., and Hill, G. E. (2007). The effect of rearing environment on blue structural coloration of eastern bluebirds (Sialia sialis). Behav. Ecol. Sociobiol. 61, 1839-1846. doi: 10.1007/s00265-007-0416-0

Siefferman, L., Hill, G. E., and Dobson, F. S. (2005). Ornamental plumage coloration and condition are dependent on age in eastern bluebirds Sialia sialis. J. Avian Biol. 36, 428-435. doi: 10.1111/j.0908-8857.2005. 03401.x

Tibbetts, E. A. (in press). The evolution of honest communication: integrating social and physiological costs of ornamentation. Integr. Comp. Biol. 
Vedder, O., Schut, E., Magrath, M. J., and Komdeur, J. (2010). Ultraviolet crown colouration affects contest outcomes among male blue tits, but only in the absence of prior encounters. Funct. Ecol. 24, 417-425. doi: 10.1111/j.13652435.2009.01660.x

White, S. B., Bookhout, T. A., and Bollinger, E. K. (1980). Use of human hair bleach to mark blackbirds and starlings. J. Field Ornithol. 51, 6-9.

Zahavi, A. (1975). Mate selection-a selection for a handicap. J. Theor. Biol. 53, 205-214. doi: 10.1016/0022-5193(75)90111-3

Conflict of Interest Statement: The authors declare that the research was conducted in the absence of any commercial or financial relationships that could be construed as a potential conflict of interest.
Received: 09 February 2014; accepted: 27 May 2014; published online: 11 June 2014. Citation: Mercadante A and Hill GE (2014) An experimental test of the role of structural blue and melanin-based chestnut coloration in aggressive contests in male eastern bluebirds. Front. Ecol. Evol. 2:24. doi: 10.3389/fevo.2014.00024

This article was submitted to Behavioral and Evolutionary Ecology, a section of the journal Frontiers in Ecology and Evolution.

Copyright (C) 2014 Mercadante and Hill. This is an open-access article distributed under the terms of the Creative Commons Attribution License (CC BY). The use, distribution or reproduction in other forums is permitted, provided the original author(s) or licensor are credited and that the original publication in this journal is cited, in accordance with accepted academic practice. No use, distribution or reproduction is permitted which does not comply with these terms. 